AJIT-e: Online Academic Journal of Information Technology

2018- Informatics and Communication Technologies Special Issue/iletişim ve Bilişsim Teknolojileri

Özel Sayı -Cilt/Vol: 9-Sayı/Num: 35

DOI: 10.5824/1309-1581.2018.5.010.x

http://www.ajit-e.org/?menu=pages\&p=details_of_article\&id=384

Received : 08.11.2018

Editorial Process Begin: 26.11.2018

Published: 20.12.2018

\title{
Teknoparklar Üzerine Bir Değerlendirme: ODTÜ Teknokent Firmalarının Etkinlik Analizi ${ }^{1}$
}

Yahya ÖZDEMiR, Yalova University, Vocational School / Turkey, yahya.ozdemir56@gmail.com

ÖZ

ODTÜ Teknokent hem bölgesel hem de uluslararası rekabet gelişme stratejilerinde Türkiye'de önemli bir inovatif kimliğe sahip olması, Türkiye'nin ihracat rakamlarına katkı sağlıyor olması, bunun yanında inovasyon güdümlü iktisadi kalkınma için önemli bir itici güç olmasından dolayı son derece önem arz etmektedir. Üniversite-sanayi işbirliğine önemli katkısı olan ODTÜ Teknokent'te üniversitesi ile firmaların bir araya gelip sinerjik bir çarpan etki oluşturdukları yüksek katma değer ürünleri uluslararası pazarlara sunan önemli bir ekosistemdir.

Bu araştırmada ODTÜ Teknokent içerisinde faaliyet gösteren firmaların mevcut yapılanmaları ve teknokent imkânları içerisindeki destek ve firsatlarla birlikte etkinlik ve performanslarn betimleyici istatistiklerle ortaya konulmaktadır. Araştırmanın temel amacı Türkiye'de faaliyet gösteren en önemli teknokentlerden birinin firma algzlamaları çerçevesinde irdelenerek mevcut durumlarının analiz edilmesidir. Bu açıdan ODTÜ teknokent firmaları faaliyet alanı, kuruluş yapısı, kuruluş yeri, faaliyet yıl, personel durumlarn gibi temel tanımlayıcı bilgilerden sonra, teknokent bünyesindeki hizmet ve desteklerden memnuniyet düzeyleri ortaya konulmuştur. Ayrıca ODTÜ teknokent firmları işbirlik, ar-ge yapılanması, ciro durumu, pazar yapısı, proje sayıları ve istihdam durumları açısından irdenlenmiştir.

Anahtar Kelimeler: ODTÜ Teknokent, İnovasyon, Ar-Ge

\footnotetext{
${ }^{1}$ Bu çalışma yazarın “Azerbaycanda Teknoparklarin Tesirinin Orta Doğu Teknik Universitesi Teknopark Modelinin Tahlili Esasinda Kiymetlendirilmesi" isimli tezden ortaya çıkarılmıştır.
} 


\section{An Evaluation on Technoparks: Impact Analysis of METU Technocity Firms}

ABSTRACT Due to the indispensable role METU Technocity plays in Turkey: facilitating regional as well as international competitive strategy development and contributing to the employment and export figures, it proved to reveal extreme importance of being a motto for innovation-driven economic development.

The goal of establishing METU Technocity is to encourage the universityindustry cooperation in creating "new knowledge", which is per se the most important constituent for the present-day competitiveness and development.

METU Technocity is an ecosystem, whereas the university-private sector joint research projects generate new strategic knowledge, which leads to high valueadded innovative goods and services being sold in the global markets.

This research presents descriptive statistics of the activity and performance of the firms operating in the METU Technocity, which get support and benefit from the opportunities provided thereof.

The main objective of this research is to analyze the performance of the firms, based on Turkey's one of the most important Technocity's firm perception.

In this respect, the operating activity, structure, place of establishment, date of activity, personnel status as well as the satisfaction level of getting benefit from technocity's services is being displayed.

In addition, METU Technocity firms have been scrutinized in terms of cooperation, RED, turnover, market structure, project numbers and employment status.

Key Words: METU Technocity, innovation, $R \mathcal{E} D$

\section{Giriş}

Yenilikçi ileri Teknoloji, üretim yöntemleri sayesinde ürünlerde üretimi ve verimliliği arttırmanın yanında, küresel çapta rekabeti tetiklemesi sürecinde bölgesel kalkınmada ve ülkelerin verimlilikleri bağlamında önemli bir yaşamsal sürece sahip olması önem arz etmektedir. Teknoloji üretim adası konumunda olan Teknoparklar uluslararası alanda hem teknolojik yenilikleri takip etmek hem de teknolojik transfer ilişkilerin kurulmasını sağlayan ekosistemdir. Teknopark içerisinde üretilen bilginin ürüne dönüşmesiyle ortaya çıkan teknoloji hem ülkenin teknolojik verimliliğini hem de küresel pazardaki rekabet gücünü etkin kılmaktadır. Gelişmiş ülkelerdeki teknoparklar katma değeri çok yüksek ürünler ortaya koymakta ve ülkenin iktisadi kalkınmasına önemli katkı sağlamaktadırlar. 
Günümüzün gelişen ekonomisinin bilişim toplumunda; sadece küresel olarak değil, aynı zamanda yenilik katan firmalarında rekabeti arttırabileceği böylelikle teknolojiyi üreten merkezlerinin ortaya koyduğu motivasyonun bu kadar neden çok önem arz ettiğini görmemiz kolaylaşacaktır.( Drucker, 1993) Daha açık bir ifadeyle küresel ekonomi gittikçe bilginin üretimi ve transferine ve de veri saklanmasına doğru bağımlı biçimde bir süreç haline gelecektir.(Buzan ve Israel, 1998;76). Bilgiyi üretecek belirleyicilerin temelinde araştırma ve geliştirmenin merkezi konumundaki yenilikçi teknoloji üretim merkezleridir.

Çalışma kapsamında öncelikle teknopark tanımının ne olduğu ortaya konulmuş ve sonrasında ise ODTÜ teknokente ilişkin bilgiler sunulmuştur. Buna göre ODTÜ teknokent firmaları faaliyet alanı, kuruluş yapısı, kuruluş yeri, faaliyet yılı, personel durumları gibi temel tanımlayıcı bilgilerden sonra, teknokent bünyesindeki hizmet ve desteklerden memnuniyet düzeyleri ortaya konulmuştur. Ayrıca ODTÜ teknokent firmları işbirlik, ar-ge yapılanması, ciro durumu, pazar yapısı, proje sayıları ve istihdam durumları açısından betimleyici istatistiklerle irdenlenmiştir.

\section{Teknopark Kavramı}

Yeniliğin merkezi konumunda olan Bilim ve teknoloji parkı kavramını ifade eden 'teknokpark' kavramı ilk defa 1950'li yıllarda A.B.D.' de ortaya çıkmış, sonrasında Avrupa ülkeleri ve diğer ülkeler tarafından rağbet görülmüş ve de sayıları her geçen gün artmıştır (Keleş, 2007:85)

“Uluslararası Bilim Parkları Birliğinin (IASP) tanımına göre "Teknoparklar, üniversite, sanayi, araştırma merkezleri, girişimciler ve piyasalar arasındaki işbirliğini artırmak, bilgi ve teknoloji transferini kolaylaştırmak suretiyle yüksek katma değerli Ar-Ge'ye dayalı ileri teknoloji ürün ve hizmetlerin üretilmesine uygun altyapı, üstyapı ve hizmetler ile katkı sağlayan organizasyonlardır". (IASP, 2014)

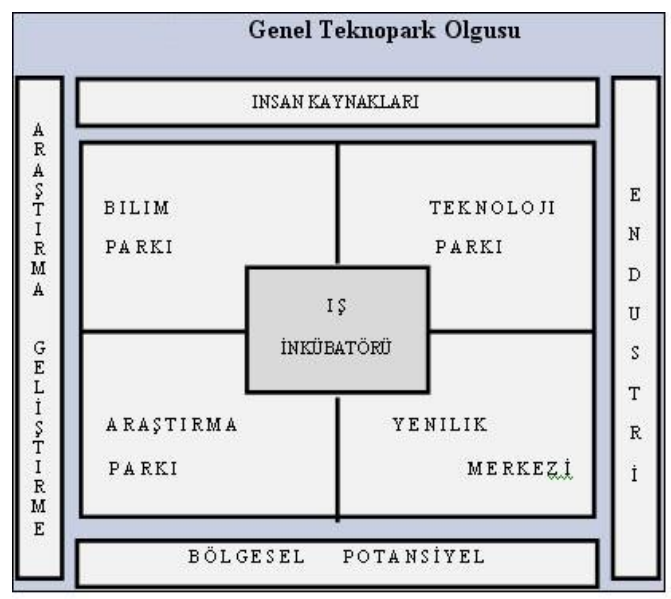

Şekil 1.1. Genel Olarak Teknopark Olgusu (Kaynak: Castells M. ve Hall P., 1995) 
Aralarında bazı farklılıklar olmanın yanında teknopark kavramı, bazı oluşumlarla aynı biçimde ifade edilebilmektedir. Araştırma parkı, teknoloji merkezi, bilim parkı, yenilik merkezi vb gibi birbirleriyle örtüşen kavramların için bir ayrım yapmak zordur ve bu terimler daha çok teknopark ile aynı manada kullanılabilmektedir. (Görkemli, 2011)

Castells ve Hall, teknoparkı istihdam sağlayan ve nitelikli kabiliyetler kazandıran ileri teknoloji firmaların bir araya gelip kümelenme oluşturan, küresel rekabette yeni koşullarda hayatta kalabilen bir endüstriyel olarak tanımlanmıştır.( Castells M., \&Hall P.,1995)

İngiltere'deki Bilim Parkları Birliği'nin yapmış olduğu teknopark tanımında; üniversite ya da araştırma merkezleri ile koordineli, yenilikçi firmaların ya da diğer kuruluşların oluşumunda etkin söz sahibi olan, bilhassa teknoloji transferi sürecinde rol alan bir yenilikçi girişimdir. . (Bakouros et al., 2002).

Teknokent yeni bilgi, finans ile işgücünün birlikte olduğu, aynı zamanda, altyapının gerekli olanaklarının içerdiği, üniversite ya da Ar-Ge merkezlerinin içerisinde ya da yakınında kurulmaktadırlar. (Teknoloji Geliştirme Bölgeleri, 2007)

\subsection{Teknoparkların Kuruluş Modelleri}

Teknopark modelleri incelendiğinde ülkeden ülkeye aynı zamada aynı ülkenin içindeki bir teknoparktan diğerine farklılıklar gösterdiği görülmektedir. Teknopark modelleri aşağıda verilmiştir. (T.C Cumhurbaşkanlığı Devlet Denetleme Kurumu, 2009)

- Devlet Odaklı: Teknoparkın kuruluşunu dolaylı biçimde devlet üstlenir.

- Üniversite Odaklı: Üniversitelerin ya tek başlarına veya devletten aldıkları destek ile kurdukları, işletip ekonomik fayda ortaya koydukları teknoparklardir.

- Özel Sektör Odaklı: Üniversiteler ile finans gücünün etkin olduğu firmalar tarafından işbirliği üzerine kurulan teknoparklardır.

- Karma Odaklı Model: Hem kamu hem de özel sektörün birlikte kurmuş oldukları teknoparklardır.

\subsubsection{ODTÜ Teknokent Tecrübesi}

ODTÜ Teknokent, üniversite ve firmalar ile birlikte ortak araştırma yenilik projeleri sonucunda ortaya yeni bilgi ve bu yeni bilginin yüksek katma değer içerikli yeni mal ve hizmetlere dönüşebildiği bir eko sistemdir. (www.magnitt.com, 2016)

Ulusal teknoloji politikalarının, teknoloji politikası temelinde uluslar arası arenada geliştirilen politikalarla eş güdüm içerisinde olması önemli bir diğer noktadır. Bu 
noktadan hareketle, ODTÜ Teknokent, IASP gibi organizasyonlarla kurmuş olduğu birliktelikler büyük önem taşımaktadır. ODTÜ Teknokentin bihassa gelecek 10 yıl süre zarfında, ülke içerisindeki aktivitelerini ve uluslar arası bağlantılarını geliştirerek evrensel bir boyuta taşımaktır. Bu hedef aynı zaman da diğer teknoparklara bir başarı hikâyesi olarak örnek teşkil edebilir. (www.odtuteknokent.com, 2016)

ODTÜ Teknokent firmalarının yurtdışına yüksek katma değerli inovatif teknoloji ihraç ettiği projelere ait birkaç örnek aşağıda verilmiştir; (www.ttgv.org.tr, 2016)

- Skorksky helikopterleri için geliştirilmiş yazılımlar

- Hem Airbus ve hem de Boeing uçakları için ortaya konulan elektronik sistemler ve yazilımlar

\subsubsection{ODTÜ Teknokent'in Amaçları}

Yükselen Türkiye Ekonomisi için geliştirilmiş yüksek katma değerli ar-ge çalışmalarını yürütmektedir. Başlıca temel amaçlar aşağıda verilmiştir. (www.odtuteknokent.com, 2016)

- Türkiye'nin teknolojik inovasyon bakımından inovatif Ar - Ge teknoloji üretebilme yeteneğini tetiklemek

- Üniversite-Sanayi işbirliğini tesis etmek,

- Üniversitede yapılan araştırmaları ekonomik değere dönüştürmek

- Girişimcilik kültürüne katkı yapmak

- Yüksek katma değer üreten sektörlerde uluslar arası boyutta öncelik vermek

- $\mathrm{AB}$ ülkeleri başta olmak üzere uluslararası işbirliğini tesis etmek

- Teknoloji transferi için uygun adımlar atmak

- İstihdama katkı vermek

\section{Araştırmanın Amacı ve Önemi}

Araştırma, teknolojik ar-ge ve inovasyonun adası durumunda olan teknoparkların bölgesel kalkınma açısından katkılarını, ODTÜ Teknokent örneği üzerinde inceleyerek teknokent firmalarının durumlarını, teknokent içerisinde verilen desteklerden memnuniyet düzeyleri ve ciro, pazara ulaşması ve ortaya koydukları istihdam açısından etkinliklerini ortaya koymayı hedeflemektedir.

\section{Araştırmanın Yöntemi}

Araştırma, ODTÜ Teknokent'in firmalar düzeyinde etkinlik algılamasını irdelemeyi amaçlamaktadır. Bu süreçte, araştırma betimleyici bir araştırma niteliğinde olup 
ODTÜ teknokent firmalarının mevcut yapılanmaları, memnuniyet ve ortaya konulan istihdam, ciro/pazar durumların frekans analizleri ile sunmaktadır. Analizler ortaya konulduktan sonra çıkan yorumlama ve değelendirmelere yer verilerek firmaların etkin güçlerini ortaya konulmaktadır. Araştırmada yüz yüze anket yöntemi sayesinde veriler istatistik paket programı yardımı ile incelenmiştir.

\subsection{Anket Soru Formunun Tanitılması}

ODTÜ Teknokent bünyesindeki firmalara mevcut durumları üç farklı açılardan (temel yapılanma, memnuniyet ve Pazar-ciro-istihdam durumları) incelemeye alınmıştır.

ODTÜ Teknokent'teki firmalar için olarak hazırlanmış anket formunda 44 adet soru bulunmaktadır. Sorulan gruptaki ilk 7, firmanın çalıştığı alan, firmanın kuruluş yapı süreci ve firmanın genel yapıdaki özellikleri irdelenmeyi amaçlamaktadır. İkinci boyutta yer alansoruları ODTÜ Teknokent içi firmaların teknokent desteklerinden memnuniyet seviyelerini ortaya koymaya yönelikken, üçüncü boyutta ise ciro, pazar payı ve istihdama ilişki sorulardan oluşmaktadır.

Anket soru formları hazırlanırken alanda uzman kişilerden görüşler alınmıştır. ODTÜ Rektör Yardımcısı ve ODTÜ Teknokent Yönetim Kurulu Başkanı Sayın Prof. Dr. Volkan ATALAY, Azerbaycan Resbuplikası İqtisadiyyat ve Senaye Nazirliyi İqtisadi İslahatlar Elmi-Tedqiqat İnstitutusu Direktörü Sayın Prof. Dr. Vilayat VALIYYEV, ODTÜ Teknokent Genel Müdür Yardımcısı Sayın Ufuk BATUM'dan bu sahada görüşleri dikkate alınarak gerekli düzeltmeler yapılarak anket formları son hali ortaya konmuştur.

\section{2. Evrenin kapsamı ve ODTÜ Teknokent Örneklemi}

Ortaya konulan çalışma, teknoparkların evreni kapsamındaki, ODTÜ Teknokent örnekleminin seçilmesi irdelenmiştir. ODTÜ Teknokent'te 96 Ar-Ge firması örneklemi içerisinde yer almaktadır.

\section{3. Araştırmanın Uygulanması}

Araştırmanın çalışma örneklemi ODTÜ Teknokent firmaları olarak belirlenmiştir. Araştırma anket formu ile ODTÜ Teknokent'te faaliyet gösteren ve ulaşılmaya çalışılan 96 firmanın her biri ile yüz yüze görüşülerekanket formu doldurulmuştur. Ulaşılan firmaların tümü, yani 96 firma anket formunu doldurmayı kabul etmiştir. Böylelikle araştırma anket soru formu firmalara yöneltilerek bilgi toplanmıştır. ODTÜ Teknokent Firmalarına yöneltilen soru anketine neticesinde elde edilen bilgiler istatistik paket programı sayesinde veri sürecine dönüştürülerek analizi yapılmıştır.

\section{4. Araştırmanın Temel Sorusu}

Araştırmada dile getirilen frekans ile diğer bazı teknikler, "ODTÜ Teknokent firmalarının mevcut durumları, memnuniyetleri ve etkinlikleri hangi seviyededir?" 
temel sorusunu test etmek için kullanılmıştır. Firmaların; ODTÜ Teknokent'ten memnuniyetleri,

- Yapmış oldukları Ar-Ge faaliyetleri bitiminde pazardaki değişme

- Yapmış oldukları Ar-Ge faaliyetlerş bitiminde yatırımdaki değişme

- Yapmış oldukları Ar-Ge faaliyetleri bitiminde cirodaki değişme

- Yapmış oldukları Ar-Ge faaliyetleri bitiminde ihracattaki değişme

- Yapmış oldukları Ar-Ge faaliyetleri bitiminde istihdamdaki değişme

- Yapmış oldukları Ar-Ge faaliyetleri üzerinden birçok kuruluşlarla yapılan teknolojik işbirliği

\section{Bulgular}

\section{Tablo 1. Firmaların Faaliyet Alanı}

\begin{tabular}{|l|c|c|}
\hline & Frekans & Yüzde \\
\hline Bilişim Teknolojileri & 68 & 70,8 \\
\hline Savunma sanayi & 28 & 29,2 \\
\hline Elektronik/Telekomünikasyon & 26 & 27,1 \\
\hline Enerji ve Çevre teknolojileri & 14 & 14,6 \\
\hline Nano teknolojileri & 3 & 3,1 \\
\hline Tasarım ve ileri malzeme & 9 & 9,4 \\
\hline Kimya & 3 & 3,1 \\
\hline Tip-Medikal-Biyomedikal & 7 & 7,3 \\
\hline Tarımsal teknoloji & 4 & 4,2 \\
\hline Gida & 1 & 1,0 \\
\hline Diğer & 17 & 17,7 \\
\hline
\end{tabular}

Tablo 1'e göre, ODTÜ Teknokent'te yer alan firmaların büyük çoğunluğu \%70,8 ile bilişim teknoloji firmaları oluşturmaktadır. ODTÜ Teknokent'in bilgi temelli olması, ABD-Silikon Vadisi Modeline benzer bir yapıya büründüğü görülmektedir. \%29,2 ile savunma sanayi firmaları, üçüncü olarak \%27,1 ve Elektronik ve telekomünikasyon firmaları mevcuttur. Firmaların birden fazla faaliyette bulunma durumu yüzdelerin dağılımında \%100 aşmaları da mevcut durumu anlamlı kılmaktadır.

\section{Tablo 2. Firmaların Kuruluş Yapısı}

\begin{tabular}{|l|c|c|}
\hline & Frekans & Yüzde \\
\hline Kurumsal (ulusal veya uluslararası) firma & 50 & 52,1 \\
\hline Öğrencilerin kurdukları start-up firma & 14 & 14,6 \\
\hline Birden çok firmanın bir araya gelip kurdukları şirket & 0 & 0 \\
\hline Üniversite dışındaki girişimcilerin gelerek kurduklarıfirma & 28 & 29,2 \\
\hline Akademisyenlerin kurmuş olduğu spin-off firma & 10 & 10,4 \\
\hline
\end{tabular}


Kuruluş sürecindeki yapıları sorulduğunda verilen cevaplar Tablo 2'de yer almaktadır. ODTÜ Teknokent'teki firmaların kuruluş yapısına bakıldığında \%52,1 ile kurumsal (ulusal veya uluslararası firma) olan firmaların çoğunlukta olduğu görülmektedir. Bunu, üniversite dışındaki girişimcilerin kurdukları firma olduğu görülmektedir. Öğrencilerin kurduğu start-up şirketleri \%14,6 ile üçüncü sırada, akademisyenlerin kurmuş oldukları spin-off firma ise \%10,4 ile dördüncü sırada yer almaktadir.

Tablo 3. Firmanızın Kuruluş Yeri

\begin{tabular}{|l|c|c|}
\hline & Freka & Yüzd \\
\hline ODTÜ Teknokent & 70 & 73,7 \\
\hline Ankara-Ostim ODTÜ Teknokent & 11 & 11,6 \\
\hline Ankara Çevresindeki iller & 5 & 5,3 \\
\hline Ülkenin diğer bölgesinde & 7 & 7,4 \\
\hline Yurt Dişında & 2 & 2,1 \\
\hline Total & $\mathbf{9 5}$ & $\mathbf{1 0 0 , 0}$ \\
\hline
\end{tabular}

Anketin uygulandığı firmanın merkezi neresidir? Sorusuna yöneltilen cevaplar Tablo 3'de görülmektedir. ODTÜ Teknokent'teki firmaların merkezlerinin daha çok Ankara olduğunu göstermektedir. Anket çalışmasına katılanların \%73,7 ve \%11,6 toplamları olan \%75,3'ü, Ar-Ge geliştirme hedefi için kurulmuş ODTÜ Teknokent firmalar, $\% 7,4$ 'ü ülkenin diğer bölgelerinde kurulan firmalardır. "Ankara çevresindeki iller" ve "Yurt dışında" seçenekleri ise üçüncü ve dördüncü sırada sırasıyla \%5,3 ve \%2,1'lik oranlarla yer almaktadır. Tablo 4'teki veriler, teknopark içinde firmaların kaç yıldır faaliyet gösterdiğini göstermektedir ki bu durum firmaların çok da eski olmadığını ortaya koyacak niteliktedir.

Tablo 4. Firmaların Teknokent İçerisindeki Faaliyet Süreleri

\begin{tabular}{|l|c|c|}
\hline & Frekans & Yüzde \\
\hline$<1$ & 15 & 15,8 \\
\hline $1-3$ & 28 & 29,5 \\
\hline $4-6$ & 22 & 23,2 \\
\hline $7-9$ & 13 & 13,7 \\
\hline $10-12$ & 14 & 14,7 \\
\hline$>12$ & 3 & 3,2 \\
\hline Total & $\mathbf{9 5}$ & $\mathbf{1 0 0 , 0}$ \\
\hline
\end{tabular}

ODTÜ Teknokent'te faaliyet gösteren firmalara kaç yıldır ODTÜ Teknokent'te faaliyet gösterdikleri sorulduğu, alınan cevaplar ise Tablo 3. 7'da yer almaktadır. Büyük kısmı \%29,5 ile 1-3 yıl arası faaliyet gösteren firmalar oluşturmuştur. Yığılma daha çok ilk üç yılda görülmektedir. Bu da gösteriyor ki, ODTÜ Teknokent her geçen yıl, firmalar tarafından çok rağbet edilen teknokent olduğu tablodan da anlaşılmaktadır. 


\section{Tablo 5. Firmaların Teknokent İçerisinde Sahip Oldukları Personel Sayısı}

\begin{tabular}{|l|c|c|}
\hline & Frekans & Yüzde \\
\hline $1-4$ & 41 & 43,2 \\
\hline $5-8$ & 11 & 11,6 \\
\hline $9-12$ & 12 & 12,6 \\
\hline $13-16$ & 7 & 7,4 \\
\hline $17-20$ & 5 & 5,3 \\
\hline$>20$ & 19 & 20,0 \\
\hline Total & $\mathbf{9 5}$ & $\mathbf{1 0 0 , 0}$ \\
\hline
\end{tabular}

ODTÜ Teknokent içerisindeki personel sayısı gözetildiğinde yüzde 43,2 ile 1-4 kişi arasında personel çalıştırdı̆̆ı sonucu ortaya çıkmaktadır. 5-8 arasında personel çalıştıran firmaların oranı ise \%11,6'dır. ODTÜ Teknokent içerisindeki firmaların az sayıda eleman çalıştırıldı̆̆ı görülmektedir.

Tablo 6. Firmaların Teknokentin Dışında Çalıştırdığı Personel Sayısı

\begin{tabular}{|l|c|c|}
\hline & Freka & Yüz \\
\hline 0 & 8 & 8,4 \\
\hline $1-3$ & 51 & 53,7 \\
\hline $4-6$ & 10 & 10,5 \\
\hline $7-9$ & 4 & 4,2 \\
\hline $10-12$ & 1 & 1,1 \\
\hline $13-15$ & 3 & 3,2 \\
\hline$>15$ & 18 & 18,9 \\
\hline Total & $\mathbf{9 5}$ & $\mathbf{1 0 0}$ \\
\hline
\end{tabular}

Tablo 6'da, firmaların ODTÜ Teknokentin kapsam dışı kaç personel olduğunu ortaya koymaktadır. Tabloda \%53,7 ile 1-3 olduğu görülmektedir. Bunun nedeni de ODTÜ Teknokent'te yer alan firmalarının \%53,7'sinin (51 adet) ODTÜ Teknokent dışı daha çok yerlerde faaliyet göstermemesinden ileri gelmektedir. ODTÜ Teknokent'in dışında kalan 15'ten çok fazla personel konumlandırdığı görülmektedir. 15'ten çok personel çalıştıran firma sayısı 18'dir.

Firmalara ODTÜ Teknokent'in hem fiziksel olanaklarından hem de sunulan destek hizmetlerinden memnuniyet ile ilgili sorular sorulmuş ve alınan cevaplar aşağıdaki Tablolarda derlenmiştir. Beşli likert değerlendirme ölçeği metodolojisi kullanılan bu çalışma sonucunda firmaların aşağıda belirtilen durumlara katılıp katılmadığı sorulmuştur. 
Tablo 7. Firmaların Teknokentin Sunduğu Çevre Düzenlemesi Hizmetinden Memnuniyet Durumu

\begin{tabular}{|l|c|c|}
\hline & Frekans & Yüzde \\
\hline Çok memnunum & 17 & 17,9 \\
\hline Memnunum & 53 & 55,8 \\
\hline Orta düzeyde memnunum & 21 & 22,1 \\
\hline Az memnunum & 2 & 2,1 \\
\hline Hiç memnun değilim & 2 & 2,1 \\
\hline Toplam & $\mathbf{9 5}$ & $\mathbf{1 0 0 , 0}$ \\
\hline
\end{tabular}

Tablo 8. Firmaların Teknokentin Sunduğu İklimlendirme Sistemi Hizmetinden Memnuniyet Durumu

\begin{tabular}{|l|c|c|}
\hline & Frekans & Yüzde \\
\hline Çok memnunum & 12 & 12,6 \\
\hline Memnunum & 45 & 47,4 \\
\hline Orta düzeyde memnunum & 28 & 29,5 \\
\hline Az memnunum & 8 & 8,4 \\
\hline Hiç memnun değilim & 2 & 2,1 \\
\hline Toplam & $\mathbf{9 5}$ & $\mathbf{1 0 0 , 0}$ \\
\hline
\end{tabular}

Tablo 9. Firmaların Teknokentin Sunduğu Güvenlik (Bina-Nizamiye güvenliği) Hizmetinden Memnuniyet Durumu

\begin{tabular}{|l|c|c|}
\hline & Frekans & Yüzde \\
\hline Çok memnunum & 27 & 28,4 \\
\hline Memnunum & 57 & 60,0 \\
\hline Orta düzeyde memnunum & 9 & 9,5 \\
\hline Az memnunum & 1 & 1,1 \\
\hline Hiç memnun değilim & 1 & 1,1 \\
\hline Toplam & $\mathbf{9 5}$ & $\mathbf{1 0 0 , 0}$ \\
\hline
\end{tabular}

Tablo 10. Firmaların Teknokentin Sunduğu Temizlik(bina, tuvalet, çevre, ortak alan) Hizmetinden Memnuniyet Durumu

\begin{tabular}{|l|c|c|}
\hline & Frekans & Yüzde \\
\hline Çok memnunum & 20 & 21,1 \\
\hline Memnunum & 55 & 57,9 \\
\hline Orta düzeyde memnunum & 14 & 14,7 \\
\hline Az memnunum & 6 & 6,3 \\
\hline Hiç memnun değilim & 0 & 0,0 \\
\hline Toplam & $\mathbf{9 5}$ & $\mathbf{1 0 0 , 0}$ \\
\hline
\end{tabular}


Tablo 11. Firmaların Teknokentin Sunduğu Yeme-İçme ve Sosyal Alanlar Hizmetinden Memnuniyet Durumu

\begin{tabular}{|l|c|c|}
\hline & Frekans & Yüzde \\
\hline Çok memnunum & 9 & 9,5 \\
\hline Memnunum & 43 & 45,3 \\
\hline Orta düzeyde memnunum & 34 & 35,8 \\
\hline Az memnunum & 7 & 7,4 \\
\hline Hiç memnun değilim & 2 & 2,1 \\
\hline Toplam & $\mathbf{9 5}$ & $\mathbf{1 0 0 , 0}$ \\
\hline
\end{tabular}

Tablo 12. Firmaların Teknokentin Sunduğu Ortak Alanlar, Bakım ve Onarım Hizmetinden Memnuniyet Durumu

\begin{tabular}{|l|c|c|}
\hline & Frekans & Yüzde \\
\hline Çok memnunum & 10 & 10,5 \\
\hline Memnunum & 58 & 61,1 \\
\hline Orta düzeyde memnunum & 23 & 24,2 \\
\hline Az memnunum & 3 & 3,2 \\
\hline Hiç memnun değilim & 1 & 1,1 \\
\hline Toplam & $\mathbf{9 5}$ & $\mathbf{1 0 0 , 0}$ \\
\hline
\end{tabular}

Tablo 3. Firmaların Teknokentin Sunduğu Danışmanlık, Eğitim, Mentorlük, Networking ve Diğer Destek Hizmetinden Memnuniyet Durumu

\begin{tabular}{|l|c|c|}
\hline & Frekans & Yüzde \\
\hline Çok memnunum & 23 & 24,2 \\
\hline Memnunum & 48 & 50,5 \\
\hline Orta düzeyde memnunum & 21 & 22,1 \\
\hline Az memnunum & 3 & 3,2 \\
\hline Hiç memnun değilim & 0 & 0,0 \\
\hline Toplam & $\mathbf{9 5}$ & $\mathbf{1 0 0 , 0}$ \\
\hline
\end{tabular}

Tablo 10-13'e göre firmaların ODTÜ Teknokent'in sunduğu çevre düzenlemerinden "memnunum" ve "çok memnunum" seçeneğini işaretleyenler \%73,7, iklimlendirme sistemi hizmetleri için \%60, güvenlik (bina-nizamiye güvenliği) hizmetleri için $\% 88,4$, temizlik (bina, tuvalet, çevre, ortak alan) hizmeti için \%79, yeme-içme vesosyal alan hizmeti için \%54, ortak alanlar, bakım ve onarım hizmeti için \%71,6, danışmanlık, eğitim, mentörlük, networking ve diğer destek hizmetleri için \%74,7 memnuniyet seviyesine ulaşılmıştır. Bu durumda en çok memnun kalınan hizmet güvenlik (binanizamiye güvenliği) iken memnuniyet durumu en az olan hizmet yeme-içme ve sosyal alan hizmetidir. Ancak verilen birçok hizmet \%70 üzerinde seyrettiği için ODTÜ Teknokentin önemli ölçüde bir fayda sağladığı gözle görülür bir biçimde verilere 
yansımıştır. Özellikle danışmanlık, eğitim, mentörlük ve networking gibi piyasa da ihtiyaç duyulan durum Teknokent tarafından sağlanmış bir hizmet olup aynı zamanda bunun memnuniyet dereceside \%100'e yakın bir sonuç oluşturmaktadır. Subjektif bakış açısı için memnun olunmamış hizmetleri incelediğimizde "hiç memnun değilim" cevabını veren 2 katılımcı çevre düzenlemelerinden memnun kalmamıştır. 2 katılımcı iklimlendirme sistemlerinden, 1 katılımcı güvenlikten, 1 katılımcı ortak alanlar, bakım ve onarım hizmetlerinden, 2 katılımcı da yeme-içme ve sosyal alan hizmetlerinden memnun kalmamış. Temizlik (bina, tuvalet, çevre, ortak alan), danışmanlık, eğitim, mentörlük, networking ve diğer destek hizmetlerinden ise hiçbir katılımcı memnuniyetsiz kalmamıştır. Normal şartlar altında anket çalışmalarında memnuniyet oranı küçük farklılıklarla öne geçerken, ODTÜ Teknokent hizmetleri sonucu oluşan memnuniyet tablosu mevcut durumu över niteliktedir. Bu durum hem firmaların başarısını hemde ülke ekonomisine yapılan katkıları artırarak küresel bazda ulusal kalkınmayı destekleyici bir rol oynamaktadır.

Firmaların "ODTÜ Teknokent bünyesindeki diğer firmalarla işbirliğine katıllyor musunuz?" ve "Ar-Ge firma stratejimizin büyük bir bölümünü oluşturur" cümlelerine katılım durumları yine beşli liket değerlendirme ölçeği metodolojisiyle belirlenmiş sonuçlar aşağıdaki Tablob 14'de gösterilmiştir.

\section{Tablo 1. Firmaların ODTÜ Teknokent Bünyesindeki Diğer Firmalarla İş Birliğine} Katılım Durumu

\begin{tabular}{|l|c|c|}
\hline & Frekans & Yüzde \\
\hline Kesinlikle Katıllyorum & 16 & 16,8 \\
\hline Katıliyorum & 60 & 63,2 \\
\hline Kararsızım & 7 & 7,4 \\
\hline Katılmiyorum & 12 & 12,6 \\
\hline Kesinlikle Katılmiyorum & 0 & 0,0 \\
\hline Toplam & $\mathbf{9 5}$ & $\mathbf{1 0 0 , 0}$ \\
\hline
\end{tabular}

Tablo 2. Firmaların Firma Stratejilerinin Büyük Bir Bölümünü AR-GE'nin Oluşturmasına Katılım Durumu

\begin{tabular}{|l|c|c|}
\hline & Frekans & Yüzde \\
\hline Kesinlikle Katıllyorum & 50 & 52,6 \\
\hline Kat1lyorum & 39 & 41,1 \\
\hline Kararsızım & 4 & 4,2 \\
\hline Katılmıorum & 2 & 2,1 \\
\hline Kesinlikle Katılmiyorum & 0 & 0,0 \\
\hline Toplam & $\mathbf{9 5}$ & $\mathbf{1 0 0 , 0}$ \\
\hline
\end{tabular}




\section{Tablo 3. Firmaların ODTÜ Teknokenti Seçme Nedenleri}

\begin{tabular}{|c|c|c|c|}
\hline \multirow{2}{*}{$\begin{array}{l}\text { ODTÜ Teknokent'i tercih etmelerindeki sebebi önceliği baz } \\
\text { alarak doldurunuz (öncelik 1, ikinci diğer öncelik 2, üçüncü } \\
\text { öncelik 3). }\end{array}$} & \multicolumn{3}{|c|}{ Öncelik Siralaması } \\
\hline & 1 & 2 & 3 \\
\hline Vergi muafiyetinin olması & 33,0 & 14,4 & 16,5 \\
\hline ODTÜ Teknokent ekosistemin sağladığı destek ve sinerji & 33,0 & 20,6 & 12,4 \\
\hline Üniversitenin prestiji & 16,5 & 26,8 & 17,5 \\
\hline Üniversite ile işbirliği olanağ & 12,4 & 18,6 & 21,6 \\
\hline $\begin{array}{l}\text { ODTÜ öğrencileri ve mezunları insan kaynağı olarak kullanma } \\
\text { imkanı }\end{array}$ & 7,2 & 10,3 & 19,6 \\
\hline ODTÜ Teknokent'in fiziksel avantajları & 5,2 & 9,3 & 8,2 \\
\hline ODTÜ Teknokent'in hizmet kalitesi & 2,1 & 5,2 & 9,3 \\
\hline
\end{tabular}

Firmalara, ODTÜ Teknokent'i tercih etme nedenleri için 1 ile 3 arakamı arasında öncelik sıralamasına göre koymaları istenmiştir. Ankete tabi tutulan firmalardan alınmış veriler ise Multiple Response analiz tekniğine göre gruplandırılarak ODTÜ Teknokent'i seçme nedenleri ortaya konmuştur. Soruya 95 katılımcının tümü cevap vermiştir. Buna göre firmaların \%33'ü "Vergi muafiyetinin olması" seçeneğini birinci sırada yer aldırmıştır. Oran olarak neredeyse aynı olan "ODTÜ Teknokent ekosistemin sağladığı destek ve sinerji" seçeneğini kalitatif mantık altında ikinci sırada değerlendirebiliriz. Çünkü katılımcıların \%20,6'sı ikinci Seçenek olarak bu durumu işaretlemiştir. Bu durumda aynı şekilde "Üniversitenin Prestiji” seçeneği ve "Üniversite ile işbirliği" seçeneğini üçüncü sıradan değerlendirebiliriz. Göreceli kıyaslarla vardığımız bu sonuç teknoparkların avantajını gözler önüne sermektedir. Veriler, ODTÜ Teknokent'i tercih etmelerindeki en büyük avantajin teknokent bünyesindeki kiralardaki fiyat avantajının bir gösterge olmasıdır. Böylelikle ekosistemin sağladığ ve insan kaynağı avantajının da bu seçime olumlu bir etken olduğunu ortaya koyduğu gözlemlenmiştir.

Tablo 4. Firmanın Teknokent Kapsamında Yıllık Cirosu

\begin{tabular}{|l|c|c|}
\hline & Frekans & Yüzde \\
\hline$<250$ & 34 & 35,8 \\
\hline $250-500$ & 14 & 14,7 \\
\hline $500-1.000$ & 13 & 13,7 \\
\hline $1.000-1.500$ & 10 & 10,5 \\
\hline $1.500-2.000$ & 11 & 11,6 \\
\hline$>2.000$ & 13 & 13,7 \\
\hline Total & $\mathbf{9 5}$ & $\mathbf{1 0 0 , 0}$ \\
\hline
\end{tabular}


Firmaların teknokent kapsamında yıllık cirosu sorulmuş 250 binden küçük olan $\% 35,8$ ile en yüksek cevabı almıştır. Bu durum Teknokentin yeni kurulmuş şirketlerden oluştuğunu göstermektedir. 250-500 cevabını veren \%14,7 ile takip etmiştir.

Tablo 58. Firmanın Teknokent Dışındaki Yıllık Cirosu

\begin{tabular}{|l|c|c|}
\hline & Frekans & Yüzde \\
\hline$<250$ & 61 & 64,2 \\
\hline $500-500$ & 3 & 3,2 \\
\hline $1.000-1.500$ & 8 & 8,4 \\
\hline $1.500-2.000$ & 2 & 2,1 \\
\hline$>2.000$ & 5 & 5,3 \\
\hline Total & 16 & 16,8 \\
\hline
\end{tabular}

Firmaların Teknokent kapsam dişı yıllık cirosu sorulmuş 250 binden küçük olan \%64,2 ile en yüksek cevabı almıştır.2 milyon TL den büyük olan 16,8'dir. Bu durum Teknokentin yeni kurulmuş şirketlerden oluşsa da tez zamanda çok büyüme yapabileceği ve bunun da Teknopark sayesinde olduğu göstermektedir.

Tablo 19. Firmanın En önemli Pazarı

\begin{tabular}{|l|c|c|}
\hline & Frekans & Yüzde \\
\hline Uluslar arası & 26 & 27,1 \\
\hline Ulusal & 66 & 68,8 \\
\hline Yerel / Bölgesel & 3 & 3,2 \\
\hline Total & $\mathbf{9 5}$ & $\mathbf{1 0 0}$ \\
\hline
\end{tabular}

Şirketlerin en önemli pazarı neresidir sorularına en yüksek cevap beklendiği gibi ulusal \%68,8 ile birinci sırada yer almaktadır. \%27,1 ile uluslar arası cevabı şirketlerin en önemli pazarını oluşturmaktadır. Uluslar arası pazarın bu kadar önem oluşturması coğrafik olarak en yakın olan ve hinterlandımızda yer alan ülkeler ile daha yoğun işbirlikleri ve teknloji transferi yapılması önem arz etmektedir.

\section{Tablo 20. Firmaların Hukuki Statüleri}

\begin{tabular}{|l|c|c|}
\hline & Frekans & Yüzde \\
\hline A.Ş. & 24 & 25,3 \\
\hline LTD & 70 & 73,7 \\
\hline DİĞER & 1 & 1,1 \\
\hline Total & $\mathbf{9 5}$ & $\mathbf{1 0 0 , 0}$ \\
\hline
\end{tabular}


Firmaların hukuki statüleri sorulduğunda limited şirkeleri \%73,7 ile birinci sırada ve $\% 25,3$ ile ikinci sırada bulunan Anonim Şirketlerini \%1,1 ile diğer şirketler takip etmektedir.

Tablo 21. Firmaların Ortaklık Durumları

\begin{tabular}{|l|c|c|}
\hline & Frekans & Yüzde \\
\hline Özel & 90 & 94,7 \\
\hline Yabanc1 & 2 & 2,1 \\
\hline Diğer & 3 & 3,2 \\
\hline Total & $\mathbf{9 5}$ & $\mathbf{1 0 0 , 0}$ \\
\hline
\end{tabular}

Şirketlerin ortaklık durumu sorusuna \%94,7 ile Özel cevabı verilmiştir.

Tablo 22. Firmaların Aile Firması Olma Durumu

\begin{tabular}{|l|c|c|}
\hline & Frekans & Yüzde \\
\hline EVET & 17 & 17,7 \\
\hline HAYIR & 78 & 81,3 \\
\hline Total & $\mathbf{9 6}$ & $\mathbf{1 0 0 , 0}$ \\
\hline
\end{tabular}

Şirketlerin \%81,3 ü aile firması değildir.

Tablo 23. Şirketlerde Devam Eden Proje Sayısı

\begin{tabular}{|l|c|c|}
\hline & Frekans & Yüzde \\
\hline $1-3$ & 62 & 65,3 \\
\hline $4-9$ & 27 & 28,4 \\
\hline $9+$ & 6 & 6,3 \\
\hline Total & $\mathbf{9 5}$ & $\mathbf{1 0 0 , 0}$ \\
\hline
\end{tabular}

Şirketlerin devam eden proje sayısı 1-3 olan \%65,3 ile ilk sirada, 4-9 arası olan $\% 28,4$ ile ikinci ve \%6,3 ile 9 ve üstü projesi olan şirketler tespit edilmiştir.

Tablo 24. Şirketlerde Biten Proje Sayısı

\begin{tabular}{|l|c|c|}
\hline & Frekans & Yüzde \\
\hline $0-4$ & 57 & 60,0 \\
\hline $5-11$ & 23 & 24,2 \\
\hline $11+$ & 15 & 15,8 \\
\hline Total & $\mathbf{9 5}$ & $\mathbf{1 0 0 , 0}$ \\
\hline
\end{tabular}

Şirketlerin biten proje sayısı 0-4 olan \%60 ile ilk sırada, 5-11 arası olan \%24,2 ile ikinci ve $\% 15,8$ ile 11 ve üstü projesi olan şirketler tespit edilmiştir. 
Tablo 6. Firmaların Yarım Kalan Proje Sayısı

\begin{tabular}{|l|c|c|}
\hline & Frekans & Yüzde \\
\hline 0 & 76 & 80,0 \\
\hline 1 & 10 & 10,5 \\
\hline $2+$ & 9 & 9,5 \\
\hline Total & $\mathbf{9 5}$ & $\mathbf{1 0 0 , 0}$ \\
\hline
\end{tabular}

Şirketlerin yarım kalan proje sayısı 0 olan \%80 ile ilk sırada, 1 olan \%10,5 ile ikinci ve $\% 9,5$ ile 2 ve üstü projesi olan şirketler tespit edilmiştir.

Tablo 7. Ar-Ge Faaliyetleri bitim sürecinde Pazardaki Artışın Beklendiğe Yer

\begin{tabular}{|l|c|c|}
\hline & Frekans & Yüzde \\
\hline Bölgesel(Ankara ve çevre iller) & 23 & 24,0 \\
\hline Uluslar arası & 50 & 52,1 \\
\hline Ulusal(Ülkenin bazı bölgeleri) & 64 & 66,7 \\
\hline
\end{tabular}

Ar-Ge faaliyetleri neticesinde pazar alanında artış beklenilen yerler için \%66,7 ile ulusal, \%52,1 ile uluslar arası ve \%24 ile bölgesel cevapları verilmiştir. \%52,1 ile uluslar arası pazar alanındaki artışın Türkiye'nin bölgesel etkinlik hedefi temelinde teknolojik ittifak yapma vizyonuna yansıması çok isabetli olacaktır.

Tablo 8. Ar-Ge Faaliyetleri Sonucunda Ek İstihdam

\begin{tabular}{|l|c|c|}
\hline & Frekans & Yüzde \\
\hline $1-5$ & 51 & 53,7 \\
\hline $6-10$ & 14 & 14,7 \\
\hline $11-15$ & 6 & 6,3 \\
\hline $21-25$ & 3 & 3,2 \\
\hline $26-30$ & 1 & 1,1 \\
\hline Ticarileşme Azald 1 & 20 & 21,1 \\
\hline Total & $\mathbf{9 5}$ & $\mathbf{1 0 0 , 0}$ \\
\hline
\end{tabular}

Ar-Ge Faaliyetleri Sonucunda Ek İstihdam sorulduğuda \%53,7 ile 1-5 ilk sirada yer almış bunu takiben \%14,7 ile 6-10 cevabı yer almıştır. Son sırada \%1,1 ile 26-30 yer almaktadir. 
Tablo 98. Ar-Ge Faaliyetleri bitiminde gelecekteki 5 Yıl İçinde İhracat Artışı Beklentisi

\begin{tabular}{|l|c|c|}
\hline & Frekans & Yüzde \\
\hline$\% 1-30$ & 41 & 43,2 \\
\hline$\% 61-90$ & 26 & 27,4 \\
\hline$\% 91-120$ & 8 & 8,4 \\
\hline$\% 121-150$ & 1 & 1,1 \\
\hline$\% 151+$ & 19 & 20,0 \\
\hline Total & $\mathbf{9 5}$ & $\mathbf{1 0 0 , 0}$ \\
\hline
\end{tabular}

Ar-Ge Faaliyetleri Sonucu 5 Y11 İçinde İhracat Artışı Beklentisi sorulduğuda \%43,2 ile \%1-30 ilk sırada yer almış bunu takiben \%27,4 ile 27,4 cevabı yer almıştır. Son sırada \%1,1 ile \%121-150 yer alırken bu durum firmaların yarıdan çoğunun ihracat artışı beklentisinin \%90'nın altında olduğunu ifade etmektedir.

Tablo 10. Firmaların Ar-Ge sürecindeki yatırımlarından Geri Dönüşün Planı

\begin{tabular}{|l|l|l|}
\hline & Frekans & Yüzde \\
\hline 1 yıldan az & 11 & 11,6 \\
\hline 1-3 yıl arasinda & 65 & 68,4 \\
\hline 4-6 yıl arasinda & 15 & 15,8 \\
\hline 6 y1ldan daha fazla & 4 & 4,2 \\
\hline Total & $\mathbf{9 5}$ & $\mathbf{1 0 0 , 0}$ \\
\hline
\end{tabular}

Şirketlerin Ar-Ge yatırımlarından Geri Dönüş Hızı Planı sorulduğuda \%68,4 ile 1-3 yıl arası ilk sırada yer almış bunu takiben \%15,8 ile 4-6 yıl arası cevabı yer almıştır. Son sırada \%4,2 ile 6 yıldan fazla yer alırken bu durum geri dönüş hızı planının genelde 4 yıldan az olacağını ifade etmektedir.

Tablo 30. Firmaların Ortak Ar-Ge Çalışması Yaptığı Kurum ve Kuruluşlar

\begin{tabular}{|l|c|c|}
\hline & Frekans & Yüzde \\
\hline ODTÜ Teknokent firmaları & 54 & 56,3 \\
\hline Yurt içi teknopark firmaları & 23 & 24,0 \\
\hline Teknopark dişı firmaları & 21 & 21,9 \\
\hline Yurt dışı firmalar & 19 & 19,8 \\
\hline Kamu kuruluşları & 20 & 20,8 \\
\hline Yurt dişı teknopark firmaları & 6 & 6,3 \\
\hline Üniversiteler & 51 & 53,1 \\
\hline Diğer & 2 & 2,0 \\
\hline
\end{tabular}

Şirketlerin Ortak Ar-Ge Çalışması Yaptığı Kurum ve Kuruluşlar sorulduğuda \%56,3 ile ODTÜ Teknokent firmaları ilk sırada yer almış bunu takiben \%53,1 ile Üniversiteler cevabı yer almıştır. Son sırada \%2,0 ile Diğer yer alırken bu durum şirketlerin ortak 
Ar-Ge çalışması yaptı̆̆ı kurum ve kuruluşların daha çok üniversite ve türevleri olduğunu ifade etmektedir. Bu sonuç her başarılı Teknokent'in arkasında başarılı üniversite olduğu bulgusunu görüyoruz.

Tablo 31. Firmaların Ar-Ge stratejisi/planı olma durumu

\begin{tabular}{|l|c|c|}
\hline & Frekans & Yüzde \\
\hline Evet & 83 & 87,4 \\
\hline Hayır & 12 & 12,6 \\
\hline Total & $\mathbf{9 5}$ & $\mathbf{1 0 0 , 0}$ \\
\hline
\end{tabular}

Şirketlerin Ar-Ge staratejisi/planı olma durumu sorulduğuda \%87,4 ile evet ve\%12,6ile hayır demiştirç Bu durum şirketlerin büyük çoğunluğunun Ar-Ge stratejisi olduduğunu gösterir. Görüldüğü gibi Teknopark'lar birer Ar-Ge adasıdır.

Tablo 32. Firmaların Teknopark İçerisindeki Çalışmaları

\begin{tabular}{|l|c|c|}
\hline & Frekans & Yüzde \\
\hline Endeksli bilimsel dergilerde & 13 & 13,5 \\
\hline Endekse girmeyen dergilerde & 17 & 17,7 \\
\hline Bilimsel yayın yapılmadı. & 69 & 71,9 \\
\hline
\end{tabular}

Firmalara yapmış oldukları faaliyetler hakkında bilimsel yayınlar yapıp yapmadıkları sorusuna firmaların \%88,4'ü bilimsel yayın yapmadığını belirtmiştir.13 tanesi $(\% 13,5)$ endeksli bilimsel dergilerde yayın yaparken, \%17,7'si endekse girmeyen dergilerde yayın yapmışlardır

\section{Tablo 11. Firmaların ODTÜ Teknokente Yerleştikten Sonra Farklı Disiplinlerde Ar-Ge Faaliyetleri Gerçekleştirme Durumu}

\begin{tabular}{|l|c|c|}
\hline & Frekans & Yüzde \\
\hline Evet & 52 & 54,7 \\
\hline Hayir & 43 & 45,3 \\
\hline Total & $\mathbf{9 5}$ & $\mathbf{1 0 0 , 0}$ \\
\hline
\end{tabular}

Tablo 124. Firmaların ODTÜ Teknokente Yerleştikten Sonra Farklı Disiplinlerde Ar-Ge Faaliyetleri Gerçekleștirme Durumu

\begin{tabular}{|l|c|c|}
\hline & Frekans & Yüzde \\
\hline $\begin{array}{l}\text { Danışmanlık hizmeti kapsamında firmada } \\
\text { üniversite personeliçalışmaktadır. }\end{array}$ & 46 & 47,9 \\
\hline Evet, ortak ya da sahipler üniversite personeli & 14 & 14,6 \\
\hline Part-time veya staj konumundaki öğrenci & 36 & 37,5 \\
\hline Hayır & 27 & 28,1 \\
\hline
\end{tabular}


Şirketlerin ODTÜ Teknokente Yerleştikten Sonra Farklı Disiplinlerde Ar-Ge Faaliyetleri Gerçekleştirme Durumu sorulduğuda, \%47,9 ile Danışmanlık hizmeti kapsamında firmada üniversite personeli çalışmaktadır. ilk sırada yer almış bunu takiben \%37,5 ile Part-time veya staj konumundaki öğrenci cevabı yer almıştır. Son sırada \%14,6 ile Evet, ortak ya da sahipler üniversite personeli yer alırken bu durum farklı disiplinlerde de Ar-Ge faaliyetleri geliştirilebileceğini ifade etmektedir.

Tablo 35. Firmaların Son Üç Yıldaki Ar-Ge Harcamaların Toplam Ciroya Oranı

\begin{tabular}{|l|c|c|}
\hline & Frekans & Yüzde \\
\hline $0-25$ & 21 & 22,1 \\
\hline $26-50$ & 36 & 37,9 \\
\hline $51-75$ & 14 & 14,7 \\
\hline $76-100$ & 14 & 14,7 \\
\hline $100+$ & 10 & 10,5 \\
\hline Total & $\mathbf{9 5}$ & $\mathbf{1 0 0 , 0}$ \\
\hline
\end{tabular}

Şirketlerin Son Üç Yıldaki Ar-Ge Harcamaların Toplam Ciroya Oranı sorulduğuda, $\% 37,9$ ile 26-50 ilk sırada yer almış bunu takiben \%22,1 ile 0-25 cevabı yer almıştır. Son sırada \%10,5 ile 100+ yer alırken bu durum son 3 yıldaki Ar-Ge harcamalarının toplam ciroya oranın düşüklügünü ifade etmektedir.

Tablo 13. Firmaların Büyüme Faktörlerinde Olumlu Olarak Yansıyan Etken ya da Etkenler

\begin{tabular}{|l|c|c|}
\hline & Frekans & Yüzde \\
\hline Ar-Ge & 77 & 80,2 \\
\hline Finansal destek & 27 & 28,1 \\
\hline Yatırımcı/Ortak & 12 & 12,5 \\
\hline Pazarın büyüklüğü & 25 & 26,0 \\
\hline Dağıtım kanalları & 6 & 6,3 \\
\hline Firma büyümemiştir. & 10 & 10,4 \\
\hline
\end{tabular}

Şirketlerin Büyüme Faktörlerinde Olumlu Olarak Yansıyan Etken ya da Etkenler sorulduğunda, \%80,2 ile Ar-Ge ilk sırada yer almış bunu takiben \%28,1 ile Finansal destek cevabı yer almıştır. Son sırada \%6,3 ile Dağıtım kanalları yer almıştır. Görülüyor ki, Ar-Ge merkezi konumunda olan teknoparklar iktisadi kalkınmada hayati önem taşımaktadır. 
Tablo 14. Teknopark içerisinde Ar-Ge Çalışmaları Neticesinde 5 Yıl İçinde Ciro Artışının olması

\begin{tabular}{|l|c|c|}
\hline & Frekans & Yüzde \\
\hline$\% 1-30$ & 18 & 18,9 \\
\hline$\% 31-60$ & 25 & 26,3 \\
\hline$\% 61-90$ & 8 & 8,4 \\
\hline$\% 91-120$ & 6 & 6,3 \\
\hline$\% 121-150$ & 5 & 5,3 \\
\hline$\% 151+$ & 33 & 34,7 \\
\hline Total & $\mathbf{9 5}$ & $\mathbf{1 0 0 , 0}$ \\
\hline
\end{tabular}

Şirketin Teknoparktaki Ar-Ge Çalışmaları Neticesinde 5 Yıl İçinde Ciro Artışı Beklentisi sorulduğuda, \%34,7 ile \%151+ ilk sırada yer almış bunu takiben \%26,3 ile\%31-60 cevabı yer almıştır. Son sırada \%5,3 ile \%121-150 yer alırken bu durum ODTÜ Teknokent şirketlerinin beklentilerinin yüksek olduğunu ifade etmektedir.

Tablo 15. Firmaların Büyüme Faktörlerinde Olumlu Olarak Yansıyan Etken ya da Etkenler

\begin{tabular}{|l|c|c|}
\hline & Frekans & Yüzde \\
\hline Bölgesel(Ankara ve civarı) & 46 & 47,9 \\
\hline Ulusal (Ülkenin diğer yerleri) & 61 & 63,5 \\
\hline Uluslar arası & 36 & 37,5 \\
\hline
\end{tabular}

Şirketlerin Büyüme Faktörlerinde Olumlu Olarak Yansıyan Etken ya da Etkenler sorulduğuda, \%63,5 ile Ulusal (Ülkenin diğer yerleri) ilk sırada yer almış bunu takiben $\% 47,9$ ile Bölgesel(Ankara ve civarı) cevabı yer almıştır. Son sırada \%37,5 ile Uluslararası yer alırken bu durum ODTÜ Teknokent şirketlerinin uluslar arası pazara ve yatırım yerlerine verdiği önemi ifade etmektedir. Göreceli olarak az gibi görünse de tablo karşılaştırmalı bir sonuç olmadığından dolayı az değildir.

Tablo 16. Firmaların Ar-Ge Desteği Aldıkları Kurum ya da Kurumlar

\begin{tabular}{|l|c|c|}
\hline & Frekans & Yüzde \\
\hline TÜBİTAK & 58 & 60,4 \\
\hline FP7 & 4 & 4,2 \\
\hline MEVKA & 0 & 0 \\
\hline SANTEZ & 5 & 5,2 \\
\hline KOSGEB & 54 & 56,3 \\
\hline TEKNOGİRIŞİM & 15 & 15,6 \\
\hline EUREKA & 3 & 3,1 \\
\hline IPARD & 0 & 0 \\
\hline TEKNOLOJİ YATIRIMCILARI (İŞ MELEKLERİ) & 2 & 2,1 \\
\hline
\end{tabular}




\begin{tabular}{|l|c|c|}
\hline TTGV & 4 & 4,2 \\
\hline DPT & 0 & 0 \\
\hline KALKINMA AJANSLARI & 10 & 10,4 \\
\hline Diğer & 4 & 4,2 \\
\hline
\end{tabular}

Şirketlerin Ar-Ge Desteği Aldıkları Kurum ya da Kurumlar sorulduğuda \%60,4 ile TUBITAK ilk sırada yer almış bunu takiben \%56,3 ile KOSGEB cevabı yer almıştır. Bu durum şirketlerin Ar-Ge desteğini aldıkları en önemli kurumların KOSGEB ve TUBITAK olduğu bulgusuna varılmıştır.

Tablo 40. ODTÜ Teknokent'te Geliştirdiğiniz Ürünler İçin Tescil Ettirdiğiniz Fikri ya da Sanayi Mülkiyet Hakları

\begin{tabular}{|l|c|c|}
\hline & Frekans & Yüzde \\
\hline Uluslararası Patent & 5 & 5,2 \\
\hline Ulusal Patent & 12 & 12,5 \\
\hline Faydalı Model & 10 & 10,4 \\
\hline Marka Tescil Belgesi & 36 & 37,5 \\
\hline Telif Hakkı ( Copy Right Tescil) & 2 & 2,1 \\
\hline Yok & 54 & 56,3 \\
\hline
\end{tabular}

Şirketlerin ODTÜ Teknokent’te Geliştirdiğiniz Ürünler İçin Tescil Ettirdiğiniz Fikri ya da Sanayi Mülkiyet Hakları sorulduğuda, \%37,5 ile Marka Tescil Belgesi ilk sırada yer almış, bunu takiben \%12,5 ile Ulusal Patent cevabı yer almıştır. Son sırada $\% 2,1$ ile Telif Hakkı ( Copy Right Tescil) yer alırken bu durum birçok firmanın ODTÜ Teknokent'te geliştirdiği ürünler için fikri ya da sanayi mülkiyet hakları tescil ettirmediklerini ifade etmektedir. Yok seçeneğinin de \%56,3 seviyesinide olması bu durumu kanıtlar niteliktedir.

Tablo 41. Firmaların Ar-Ge çalışmalarına dayalı Üniversite Dışındaki Kamu Kuruluşları ile Ortak Eğitim ve Seminer Faaliyetlerinin Olma Durumu

\begin{tabular}{|l|c|c|}
\hline & Frekans & Yüzde \\
\hline Evet & 33 & 34,7 \\
\hline Hayır & 62 & 65,3 \\
\hline Total & $\mathbf{9 5}$ & $\mathbf{1 0 0 , 0}$ \\
\hline
\end{tabular}

Şirketlerin ortaya koyduğu Ar-Ge çalışmaları ile ilgili olarak üniversite dışındaki bir çok kuruluşlar ile beraber ortak eğitim ve seminer faaliyetlerinin olup olmama durumuna şirketlerin \%34.7'si evet, \%65.3'ü hayır demiştir. 
Tablo 42. Firmaların Kamu Kuruluşlarıyla Ortak Proje Çalışmaları

\begin{tabular}{|l|c|c|}
\hline & Frekans & Yüzde \\
\hline EVET & 37 & 39,6 \\
\hline HAYIR & 58 & 60,4 \\
\hline
\end{tabular}

Şirketlerin Kamu Kuruluşlarıyla Ortak Proje Çalışmaları sorulduğuda \%39,6 ile evet ve \%60,4 ile hayır denmiştir. Bu durum firmaların yarısından fazlasının kamu kurumlarıyla iş yapmadığını göstermiştir. Firmaların belirttiği ortak proje isimleri liste halinde aşağıda verilmiştir,

- ABB ile Sanal kampüs projesi, Mavi Masa, Tesmer, TEOS

- A

- Aldığımız ihaleler

- Belediye vb..

- Botaş ile rms a istasyonlarındaki basınç düşürme otonmastyon işlerinde genelde birlikte çalışıyoruz

- Çeşitli üniversiter ile arge projesi

- Ders Müfredatı Oluşturma ve Uygulama

- DSİ Paydaş Analizi

- Eğitim ve bilgilendirme platformları, hizmet içi eğitim içerikleri

- Emniyet Genel Müdürlüğü Suç Analiz Merkezi, Tapu Kadastro Genel Müdürlüğü TAKBİS Sistemi, Tarım Bakanlığı NİİS Sistemi, Enerji Bakanlığı En-Ver Portali, DPT Portali, TSK vb.

- Gizli

- GörenGöz - Ulaştırma Bak.

- iş Uygulamaları Yazılımları

- Karayolları Genel Müdürlüğü ile birlikte yürütülen KAMAG projesi

- Karayolları Köprü Yönetim Projesi

- Kayıtlı Elektronik Posta, BTK, PTT, Adalet Bakanlığı, Kalkınma Bakanlığ1

- Maliye Bakanlığ 1 SGB NET

- MEB Fatih Projesi, TUBİTAK, Aselsan

- Mobil uygulamalar

- ODTÜ Gida Mühendisliği San-tez

- ODTÜ BBS

- Orman Bakanlıgı, Sıvıl Havacılık Genel Müdürlüğü, Emniyet Genel Müdürlüğü, Sanayi ve Ticaret Bakanlığı

- Sağlık Bakanlığı Sıcaklık Takibi

- SAN-TEZ

- Savunma Sanayi Müsteşarlığı, Milli Savunma Bakanlığı

- Süreç Modelleme, Ontoloji

- Tanıtım Projeleri İçin Destek 
- Teklif aşamasında

- TEMSAN

- Test Düzeneği Tasarım ve Üretimi

- TSE - Ortak Kriterler konusunda beraber proje geliştirmekteyiz.

- TUBİTAK TEYDEB, TUBİTAK SAVTAG

- Tübitak - Malware Değişim

- TÜBİTAK adına çok sayıda projede görev alıyoruz.

- Üniversite

- Yazılım alt yapisı

Tablo 17. Firmaların ODTÜ Teknokent Bünyesindeki Çalışmaları ile İlgili Karşılaştıkları Zorluklar

\begin{tabular}{|l|c|c|}
\hline & Frekans & Yüzde \\
\hline Bir güçlükle karşılaşmadım & 41 & 42,7 \\
\hline Nitelikli Ar-Ge personeli istihdamı & 36 & 37,5 \\
\hline $\begin{array}{l}\text { Ar-Ge projelerine finansman desteğin } \\
\text { sağlanamaması }\end{array}$ & 20 & 20,8 \\
\hline $\begin{array}{l}\text { Ortaya konulan Ar-Ge projelerinin ticarileşmesi } \\
\text { sürecinde desteğin bulunma sıkıntısı }\end{array}$ & 31 & 32,3 \\
\hline Danışmanlık hizmetinin alınamaması & 5 & 5,2 \\
\hline Laboratuar ile ilgili sıkıntılar & 11 & 11,5 \\
\hline Teknopark yönetim ile olan ilişkilerde & 0 & 0 \\
\hline Diğer & 5 & 5,2 \\
\hline
\end{tabular}

ODTÜ Teknokent'te yer alan firmalara yöneltilen ankette en son sorulardan birisi de Ar-Ge faaliyetleri sırasında karşılaşılan güçlüklerdir. Yüzde 37,5'i karşılaşılan güçlükler olarak nitelikli Ar-Ge personeli istihdamı seçeneğini öne çıkarmışlardır. yüzde 20,8 ile Ar-Ge projesinin ticareileşmesi sürecinde destek bulma sıkıntısı olmuştur. Yüzde 42,7'si ise hiçbir zorlukla karşılaşmadıkları gözlemlenmiştir. (Tablo 43).

Tablo 18. Firmaların Yüzde Bazlı Lisanüstü Personel Çalıştırma Durumu

\begin{tabular}{|l|c|c|}
\hline & Frekans & Yüzde \\
\hline $0-20$ & 46 & 48,4 \\
\hline $21-40$ & 20 & 21,1 \\
\hline $41-60$ & 9 & 9,5 \\
\hline $61-80$ & 9 & 9,5 \\
\hline $81-100$ & 11 & 11,6 \\
\hline Total & $\mathbf{9 5}$ & $\mathbf{1 0 0 , 0}$ \\
\hline
\end{tabular}

Şirketlerin Yüzde Bazlı Lisanüstü Personel Çalıştırma Durumu sorulduğuda, \%48,4 ile 0-20 ilk sırada yer almış bunu takiben \%21,1 ile 21-40 cevabı yer almıştır. Son sırada 
\%9,5 ile 41-60 ve 61-80 eşit yüzdeyle yer alırken bu durum her 2 firmadan birinde firma çalışanlarının en az beşte birinin lisansüstü olduğunu ifade etmektedir.

\section{Sonuç ve Değerlendirme}

Ülke toplumlarının ekonomi ve teknoloji alanındaki gelişmişlik düzeylerinin önem arz eden faktörlerden biri, ülkelerin sahip oldukları yüksek katma değerli ileri teknolojilerdir. İleri Teknolojik ilerleme, hem ülkeler hem de firmalar açısından uluslararası arenada rekabet edebilirliğin göstergesidir.

İnovatif Teknoparkların iktisadi kalkınmaya olumlu sonuçları ODTÜ Teknokent örneği üzerinde yapıldığg bu çalışmada, anketler firmalara uygulanmış böylelikle inovatif Ar-Ge bölge ekonomisine olumlu etkileri, bilhassa ihracatın, yatırım süreci, cirodaki değişim, istihdamdki değişme ve de pazardaki genişleme alanı olmak üzere birçok önemli nokta betimleyici yöntemle analiz edilmiştir.

Uygulanan analizler neticesinde;

- Türkiye'nin en önemli teknokentlerinden biri konumundaki ODTÜ Teknokentte yer alan işletmelerin yarısının kurumsal işletme durumunda olduğu tespit edilmiştir. Bu teknokent bünyesinden çıkacak olan yeni veyenilikçi ürünlere dosğrudan kurumsal desteğin sağlanmasından dolayı önemli bir göstergedir. Yine benzer biçimde öğrenci öbeklenmesini ortaya koyan \%14'lük bir oranda öğrenci işletmelerinin olması da yenilikçi fikirlerin yeşermesine katkı bağlamında önemlidir.

- OTDÜ teknokent bünyesindeki işletmelerin teknokent bünyesinde 7 yıl ve üzeri faaliyet gösteren işletme oranı \% 31,6 civarlarındadır. Bu oran teknokent bünyesindeki sürüdülebilirliğe yönelik bir işaret olarak algilanabilir.

- ODTÜ teknokentin işletmelere sunduğu çevre düzenlemeleri, ikilmlendirme olanakları, güvenlik hizmetleri, temizlik hizmetleri, sosyal ve rekreasyon alanları, bakım ve onarım hizmetleri, danışmanlık, eğitim ve networking faaliyetleri gibi kurumsal desteklerden son derece memnun oldukları saptanmıştır. Bu bilginin yeşermesi ve olgunlaşarak ticari bir faaliyet haline dönüşebilmesi için uygun bir ekosistemin varlığına işaret etmektedir.

- ODTÜ teknokent bünyesindeki işletmlerin kendi aralarındaki sinerjiden de yüksek düzeyde faydalandıkları belirlenmiştir.

- ODTÜ teknokent işletmelerinin yoğunlukla ar-ge temelli işletmler olduğu ve bunun ulusal yenilik ve kalkınma politikalarımızla uyumlu olduğu görülmektedir.

- ODTÜ teknokent işletmelerinin büyük oranda $(\% 68,8)$ ulusal ve önemli oranda da $(\% 27,1)$ uluslararası hedef pazarlarda faaliyet gösterdikleri 
belirlenmiştir. Buna göre ulusal ve endüstriyel çıkarlarımız temelinde bu faaliyet gösterilen pazarların önemli olduğu söylenebilir. Yani işletmelerin uluslararası yada en azından ulusal büyüklükte faaliyet gösterdikleri söylenebilir.

- Ar-Ge çalışmaları sonucunda oluşacak yeni pazarlar konusundaki ODTÜ teknokent işletmelerinin beklentilerinin yaklaşık olarak yarısınının $(\% 52,1)$ uluslararası düzeyli olması geleceğe yönelik büyüme hedefleri olan işletmleri göstermesi bakımından önemlidir.

- ODTÜ teknokent firmalarının ar-ge faaliyetlerine yönelik olarak 1-10 arasında istihdama katkı yapabilceklerini belirtmeleri ekonomik ve toplumsal beklentilere cevap niteliğinde olması da önemlidir.

- ODTÜ teknokent işletmelerinin \%27,4 ünün \%61 ila 90 aralığında ihracat artışı beklentisi güven veren bir sonuç olarak değerlendirilebilir.

Yapılan bütün analizlerden oratay çıkan bulgular; teknoparkların içerisinde ortaya konulan ileri teknolojik ürünlerin ülkenin ekonomisine önemli çarpan etki oluşturduğu, ODTÜ Teknokent modeli gibi uluslararası deneyimine sahip teknopark sayılarının arttırılması, güçlü bir ülke ekonomisinin oluşumu için önemli bir katkıdır. 


\section{Kaynakça}

Bakouros, Y., L., Mardas, D., C., and Varsakelis, N., C., (2002), "Science Park A High Tech Fantasy : An Analysis of The Science Park of Greece", Technovation, 22: pp: $123-128$

BUZAN, Tony and Israel, Richard (1998), Beyinle Satış, İstanbul.

Castells M., ve Hall P., (1995) Technopoles of the World: The Making of TwentyFirst-Century Industrial Complexes, London and New York: Routledge Pub.

Görkemli H. Nur, (2011) T.C. Selçuk Üniversitesi Sosyal Bilimler Enstitüsü İktisat Anabilim Dalı, “Bölgesel Kalkınmada Teknoparkların Önemi Ve Konya Teknokent Örneği", Doktora Tezi, Konya.

KELEŞ, Murat Kemal (2007): Türkiye'de Teknokentler: Bir Ampirik İnceleme, Süleyman Demirel Üniversitesi, Basılmamış Y.L.T., Isparta.

IASP (International Association of Science Parks), (2002), www.iasp.org (( internet adresinden 2014 yılında edinilmiştir.)

T.C Cumhurbaşkanlığı Devlet Denetleme Kurumu, (2009) “4691 Sayılı Teknoloji Geliştirme Bölgeleri Kanunu Uygulamalarının Değerlendirilmesi ile Uygulamada Ortaya Çıkan Sorunların Çözümüne İlişkin Öneri Geliştirilmesi Araştırma Raporu", Sayı:1, ss.109-135, Ankara.

Teknoloji Geliştirme Bölgeleri, Sanayi Araştırma ve Geliştirme Genel Müdürlüğüu, Slayt,

http://www.sanayi.gov.tr/webEdit/gozlem.aspx?menuSec=202\&sayfaNo=253 5\&E.T: 11.11.2007 16 SARIHAN, s. 153

http://tekmer.metu.edu.tr ( internet adresinden 2015 yılında edinilmiştir.) http://www.me.metu.edu.tr/people/ozguven/ ( internet adresinden 2014 y1lında edinilmiştir.)

http://www.stradigma.com/turkce/eylul2003/makale_10.html ( internet adresinden 2015 yılında edinilmiştir.)

www.odtuteknokent.com (internet adresinden 2016 yılında edinilmiştir.) www.ttgv.org.tr ( internet adresinden 2016 yılında edinilmiştir.) www.magnitt.com ( internet adresinden 2016 yılında edinilmiştir.) 